\title{
Population-based health survey in Eastern region of Saudi Arabia
}

R. Rehmani, ${ }^{1}$ A.G. Elzubair, ${ }^{2}$ M. AlMaani, ${ }^{3}$ I.Y. Chaudary, ${ }^{4}$ A. Al Qarni, ${ }^{2}$ T. Khasshogi ${ }^{5}$ and A. Al Shuaibi ${ }^{6}$

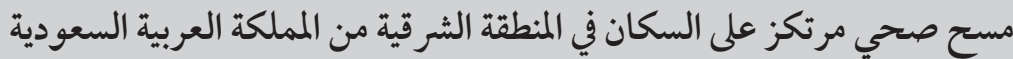

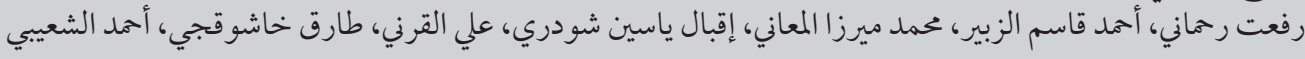

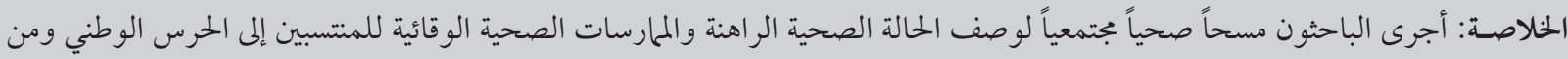

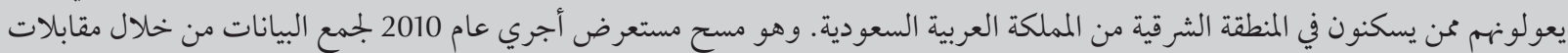

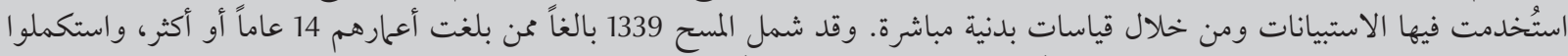

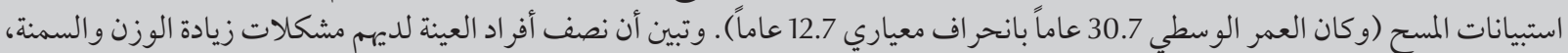

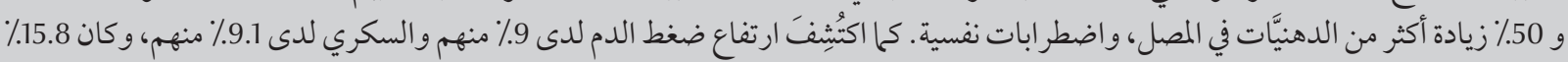

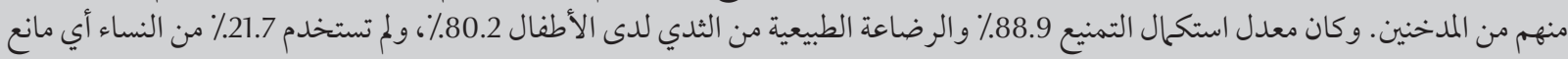

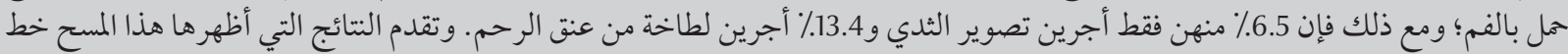

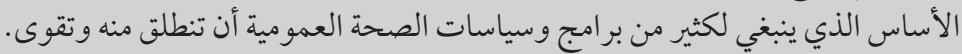

ABSTRACT A community health survey was conducted to describe the current health status and preventive health practices of National Guard military employees and their dependants residing in the Eastern region of Saudi Arabia. In a cross-sectional survey in 2010, data were collected via a questionnaire interview and direct physical measurements. A total of 1339 adults aged $\geq 14$ years completed the survey [mean age 30.7 (SD 12.7 ) years]. About two-thirds of the sample had problems of overweight and obesity, while $50 \%$ had high serum lipids and psychiatric disorders. Hypertension and diabetes were detected in $9.0 \%$ and $9.1 \%$ of the participants respectively and $15.8 \%$ were smokers. The rates of complete immunization and breastfeeding of children were $88.9 \%$ and $80.2 \%$ respectively and $21.7 \%$ of the women had ever used oral contraceptives. However, only $6.5 \%$ of the women had ever had a mammogram and $13.4 \%$ a cervical smear. The survey results provide a baseline from which to strengthen many public health policies and programmes.

\section{Enquête de santé en population générale dans la région est de l'Arabie saoudite}

RÉSUMÉ Une enquête de santé communautaire a été menée pour évaluer l'état de santé actuel ainsi que les pratiques de santé préventive des employés militaires de la Garde nationale saoudienne et de leurs personnes à charge dans la région est de l'Arabie Saoudite. Dans une enquête transversale menée en 2010, des données ont été recueillies par questionnaire administré lors d'un entretien et par des mesures physiques directes. Près de deux tiers des personnes souffraient de surpoids et d'obésité et la moitié d'une hyperlipidémie sérique et de troubles psychiatriques. Une hypertension et un diabète ont été dépistés chez 9,0\% et 9,1\% des participants respectivement tandis que 15,8\% étaient fumeurs. Au total, 1339 adultes de 14 ans ou plus ont répondu à l'enquête (âge moyen 30,7 ans [ET 12,7]). Au total, 88,9 \% des enfants avaient un statut vaccinal complet, 80,2 $\%$ avaient été allaités au sein et $21,7 \%$ des femmes avaient déjà eu recours aux contraceptifs oraux. Toutefois, seules 6,5\% des femmes avaient déjà bénéficié d'une mammographie et 13,4\% d'un frottis du col. Les résultats de l'enquête fournissent une base de données initiales utile pour renforcer de nombreux programmes et politiques de santé publique. 


\section{Introduction}

According to the World Health Organization (WHO), health is defined as a state of complete physical, mental and social well-being and not merely the absence of disease or infirmity and should enable people to lead socially and economically productive lives [1]. Globally, policy-makers, provincial health departments, researchers and health professionals are all agreed that a comprehensive source of accurate health measures is essential to assist them in addressing the health needs of their nation. Classic examples of comprehensive health surveys are the Demographic and Health Surveys conducted in many countries worldwide [2] and the Canadian Health Measures Survey [3].

Previous national health surveys in Saudi Arabia have not covered a compete range of nutrition, physical activity habits, family medical history, current and past medical conditions, healthrelated risk factors and topics related to women's and children's health [4-6]. The National Guard Health Affairs (NGHA) provides modern medical care for military employees and their dependants and is active in promoting disease prevention and the adoption of healthy lifestyles [7]. Based on the regional need and the mission of NGHA, a community health survey was conducted to describe the current health of the inhabitants of National Guard housing. We believed our sample to be equivalent to a national representative sample, as National Guards are recruited from all regions of Saudi Arabia. No population-based study has been done in this particular group, and there is a gap in our knowledge regarding the prevalence of major health problems and the preventive health practices of this population. The general aim of the study was to obtain accurate and up-to-date information on the health status and preventive health practices of National Guard housing inhabitants that would act as baseline community health data for regional planning. The specific objectives were to evaluate the extent of health problems associated with major health concerns (such as diabetes, obesity, hypertension, cardiovascular disease) and to assess health lifestyles and practices and participation in prevention and screening.

\section{Methods}

\section{Study design and setting}

The National Guard Health Measures Survey 2010 (NGHMS-2010) was a cross-sectional study using household interviews and direct physical measurements. A survey of the selected households was conducted from May to October 2010 at 2 National Guard housing complexes in the Eastern region of Saudi Arabia, one in Al-Hasa and other in Dammam. All adults, aged 14+ years, living in National Guard housing were included in the survey. Children aged $<14$ years and adult visitors were excluded.

\section{Sample}

The study population was the National Guard military employees and their eligible dependants residing in National Guard housing in Al-Hasa and Dammam. The National Guard housing was the primary sampling frame and formed the starting point for the sampling procedure. They are subdivided into 9 administrative districts and samples were selected from each district. Based on the probability proportional to size, a fixed number of households were selected from the household list in each of the selected districts, and all household members in the eligible age group in the selected household were selected for the survey.

A household (individual sharing a cooking area) was used as the sampling unit. There were a total of 3756 households (2506 in Al-Ahsa and 1250 in Dammam). Our calculations resulted in a sample size of 349 households, for a type 1 error rate of $0.05,5 \%$ margin of error. Assuming a non-response rate of $20 \%$, the final sample size was 419 households (280 in Al-Ahsa, and 139 in Dammam).

\section{Data collection}

The NGHMS-2010 was carried out at the primary health centres (PHC) in Al-Hasa and Dammam. Sampled households were notified by phone and the interviewers contacted the head of the family to create a list of household members and then select a respondent. Once a respondent from each household was selected and agreed to participate, an appointment was made at the PHC. Data collection was performed in 2 stages: a health questionnaire administered by trained interviewers and direct physical measurements and collection of blood samples.

The pre-coded questionnaire, based on the Health Measures Survey, is a reliable and validated tool [3]. It was translated into Arabic and was pre-tested and validated in the current context in a pilot study. The questionnaire has 15 modules covering topics such as nutrition, physical activity habits, family medical history, current and past medical conditions, health-related risk factors and topics related to women's and children's health. The interviews took about 60 minutes on average to administer.

Data were collected about exercise (exercise undertaken for fitness, recreation or sport in the 30 days prior to interview); hygiene practices (regularly washing hands before eating within the last 30 days); serious injuries (suffered injury which caused loss of at least 1 full day of usual activities such as school, sports or a job or required treatment by a doctor or nurse within the last 30 days); and psychiatric problems (selfreported presence of a range of depressive symptoms and emotional distress using the Centre for Epidemiologic Studies Depression scale [8]). Married women answered questions about 
prevention and screening practices: immunization (complete immunization of their children with 6 vaccines BCG, polio, diphtheria, tetanus, pertussis and measles); breastfeeding (breastfed their children for at least 6 months); screening (ever had a mammogram or cervical smear, self-reported and validated from medical records); and contraceptive use (ever used oral contraceptive pills).

A clinical examination was performed, and blood pressure, weight and height were measured by the nurses. Weight was measured using domestic scales with indoor clothing without shoes on to the nearest $0.1 \mathrm{~kg}$. Height measurement was carried out to the nearest $\mathrm{mm}$ by using a measuring tape. Trained technicians collected a $20 \mathrm{~mL}$ of fasting blood (12-hour fasting) into 2 tubes of $10 \mathrm{~mL}$ each. The laboratory data collected included fasting plasma glucose (FPG), fasting lipids and glycosylated haemoglobin (HbAlc) levels (on diabetic patients only).

\section{Quality control measures}

Quality control measures were built into the survey design to ensure accuracy, completeness and comparability of information across the facilities. These included development of a training manual of standardized procedures; training of coordinators and interviewers in clinical measurement and questionnaire completion to provide consistency of techniques; and scheduled replication of measurements by survey supervisors. The field supervisor supervised the interviewers in 10\% of all the patient interviews. For every 50th person visiting the clinic, all clinical measurements were repeated blindly by another interviewer, and 2 blood samples were submitted to the laboratory without identifiable linkage to check the quality of laboratory procedures.

\section{Definitions}

Diabetes was determined based on levels proposed by the American Diabetic Association (ADA) and adopted by the WHO as follows: normal blood glucose $($ FPG $<6.1 \mathrm{mmol} / \mathrm{L})$, impaired fasting glucose (FPG 6.1-6.9 $\mathrm{mmol} / \mathrm{L}$ ) and diabetes mellitus (FPG $\geq 7.0 \mathrm{mmol} / \mathrm{L}$ or random plasma glucose $\geq 11.1 \mathrm{mmol} / \mathrm{L}$ ) [9]. Blood pressure was measured with a mercury sphygmomanometer according to the standardized protocol recommended by the American Heart Association [10]. Hypertension was defined as a systolic blood pressure $\geq 140 \mathrm{mmHg}$ or greater or a diastolic blood pressure $\geq 90 \mathrm{mmHg}$ (based on the mean of the 2 readings) or current therapy with anti-hypertensive medication. Body mass index (BMI) was calculated as weight in kilograms divided by the square of height in metres. According to the National Institutes of Health guidelines [11], weight status was classified into following BMI categories: underweight $\left(\leq 18.5 \mathrm{~kg} / \mathrm{m}^{2}\right)$, normal weight $\left(18.5-24.9 \mathrm{~kg} / \mathrm{m}^{2}\right)$, overweight $\left(25-29.9 \mathrm{~kg} / \mathrm{m}^{2}\right)$, obesity $(\geq 30 \mathrm{~kg} /$ $\left.\mathrm{m}^{2}\right)$ and gross obesity $\left(\geq 40 \mathrm{~kg} / \mathrm{m}^{2}\right)$. Hyperlipidaemia was defined as serum cholesterol $>5.2 \mathrm{mmol}$, or low-density lipoprotein cholesterol $>3.4 \mathrm{mmol}$, or serum triglycerides $>1.7 \mathrm{mmol}$. People were grouped into 3 exercise levels period: high (1+ hours of vigorous exercise during the last 1 week), moderate (< 1 hour of vigorous exercise) and low/ sedentary (no exercise or little exercise in the 30 days prior to interview).

\section{Ethical issues}

The study proposal was approved by the institutional review board. All information provided by the interviewers was strictly confidential. All records were securely stored and locked to restrict access only to study staff. A prospective participant in the survey was informed about the proposed survey before any consent to participate was considered valid. Participation on the study was voluntary; respondents could decline any test or withdraw at any time.

\section{Data analysis}

The data were entered into a personal computer and SPSS, version 16.0, was used for data analysis. Descriptive statistics was used to summarize the data and to describe the prevalence of common problems in the study group.

The significance of relationship of the items related to lifestyle and prevention practices, health problems and prevention and screening practices with sex, age, education level, mothers' working status and family size was assessed using the chi-squared test. For this purpose age was categorized as $<35$ or $\geq$ 35 years, education level as high or low, mothers' working status as working or housewife and family size as 4, 4-7 and $>7$ members.

\section{Results}

Of the total of 2054 individuals residing in a sample of 419 houses, 1869 (91.0\%) were located. Of these, a total of $1339(71.6 \%)$ adults completed the survey. Their mean age was 30.7 (SD 12.7) years.

\section{Demographic data}

Regarding participants' profile, just over $50 \%$ of participants werein the age group 14-34 years, while $<2 \%$ were aged $55+$ years. Males comprised $57.4 \%$ of the studied group. Almost three-quarters of the sample had a low or medium level of education, and the most common family size was 4-7 members (Table 1).

\section{Lifestyle and preventive measures practices}

A great majority of the participants (93.1\%) expressed satisfaction with their health. Physical exercise, hand washing, daily bathing and daily tooth brushing were practised by a majority of the sample. However, $15.8 \%$ of the sample reported that they were smokers (Table 2).

The rate of health satisfaction was significantly higher among males and those aged $<35$ years $(P<0.002$ and $<0.001$ respectively). Similarly practising physical exercise was reported by 


\begin{tabular}{|c|c|c|}
\hline \multicolumn{3}{|c|}{$\begin{array}{l}\text { Table } 1 \text { Demographic profile of participants in the National Guard Health } \\
\text { Measures Survey } 2010 \text { in Eastern region of Saudi Arabia }(n=1339)\end{array}$} \\
\hline Variable & No. & $\%$ \\
\hline \multicolumn{3}{|l|}{ Age (years) } \\
\hline $14-24$ & 498 & 37.2 \\
\hline $25-34$ & 253 & 18.9 \\
\hline $35-44$ & 399 & 29.8 \\
\hline $45-54$ & 166 & 12.4 \\
\hline $55+$ & 23 & 1.7 \\
\hline \multicolumn{3}{|l|}{ Sex } \\
\hline Male & 769 & 57.4 \\
\hline Female & 570 & 42.6 \\
\hline \multicolumn{3}{|l|}{ Education level } \\
\hline Low (grade 1-6) & 596 & 44.5 \\
\hline Medium (grade 7-9) & 431 & 32.2 \\
\hline High (grade $\geq 10$ ) & 312 & 23.3 \\
\hline \multicolumn{3}{|l|}{ Family size } \\
\hline$<4$ & 142 & 13.4 \\
\hline $4-7$ & 666 & 63.0 \\
\hline$>7$ & 250 & 23.6 \\
\hline
\end{tabular}

significantly more males, those aged $<35$ years $(P<0.001$, and $<0.001$ respectively) and with family size $<7$ ( $P$ $<0.02$ ). The practice of daily bathing and daily tooth brushing did not show significant variation across the variables. The practice of hand washing was reported by significantly more males, those aged $\geq 35$ years and those with higher education level $(P<0.007$, $<$ 0.001 and $<0.02$ respectively). On the other hand, smoking was reported by significantly more males, those aged $\geq$ 35 years and those with family size $\geq 7$ members $(P<0.001,<0.01$ and $<0.04$ respectively).

\section{Health problems}

Around two-thirds of the sample had problems of overweight and obesity, while 50\% had high serum lipids and psychiatric problems. Hypertension and diabetes were present in just under $10 \%$ of the sample in both cases; and a few individuals (6.0\%) had suffered a serious accident (Table 3 ).

We found that $31 \%$ of participants had 1 or more of the major risk factors for cardiovascular disease (high blood cholesterol, diabetes, high blood pressure and smoking), while $10 \%$ of participants had 2 major risk factors.

Overweight or obesity was significantly more common among males $(P<0.02)$, raised serum lipids among males and participants aged $\geq 35$ years $(P<0.001$ and $<0.001$ respectively $)$ and diabetes mellitus among males, those aged $\geq 35$ years and those with family size $\geq 7$ members $(P<0.001,<0.001$ and $<0.03$ respectively). The rate of hypertension was also significantly higher among subjects aged $\geq 35$ years $(P<$ $0.001)$. Serious accidents were suffered by significantly more males $(P<0.009)$. In contrast, psychiatric problems were present in significantly more females, those aged $<35$ years, and those with family size of $\geq 7$ members $(P<0.001,<$ 0.01 , and $<0.02$ respectively).

\section{Prevention and screening practices}

Married women answered questions about prevention and screening practices. High rates of complete immunization of their children and breastfeeding their children for at least 6 months ( $88.9 \%$ and $80.2 \%$ respectively) were found, while $21.7 \%$ of women had ever used oral contraceptives and very few had ever had a mammogram or cervical smear (Table 4).

Adequate childhood immunization and breastfeeding practices was found among significantly more women aged $<35$ years $(P<0.001$ and $<0.01$ respectively). A cervical smear had been obtained by significantly more women aged $\geq 35$ years $(P<0.005)$. However, having ever had a mammogram or ever used oral contraceptive pills did not show a significant variation with woman's age, education level, mothers' working status or family size.

\section{Discussion}

The findings of the NGHMS-2010 have described the prevalence of health problems and use of preventative health practices among the studied group of National Guard military employees and their dependants. It provides an excellent base from which to strengthen many public health policies and programmes. These results help in the identification and selection of priority health issues at a regional level. Based on these very important issues, relevant health indicators can be selected and monitored.

\section{Lifestyle and preventive measures practices}

Physical activity can reduce the likelihood of a person developing heart disease, high blood pressure, osteoporosis and possibly diabetes [12]. It can also have a positive effect on a person's overall wellbeing, mental health and self-image. Physical inactivity is an established risk factor for cardiovascular disease, cancer and diabetes. A literature review in 2004 concluded that the prevalence of physical inactivity among Saudi children, adolescents and adults was high [13]. A recent study in Taif, Saudi Arabia found that $54 \%$ of the 


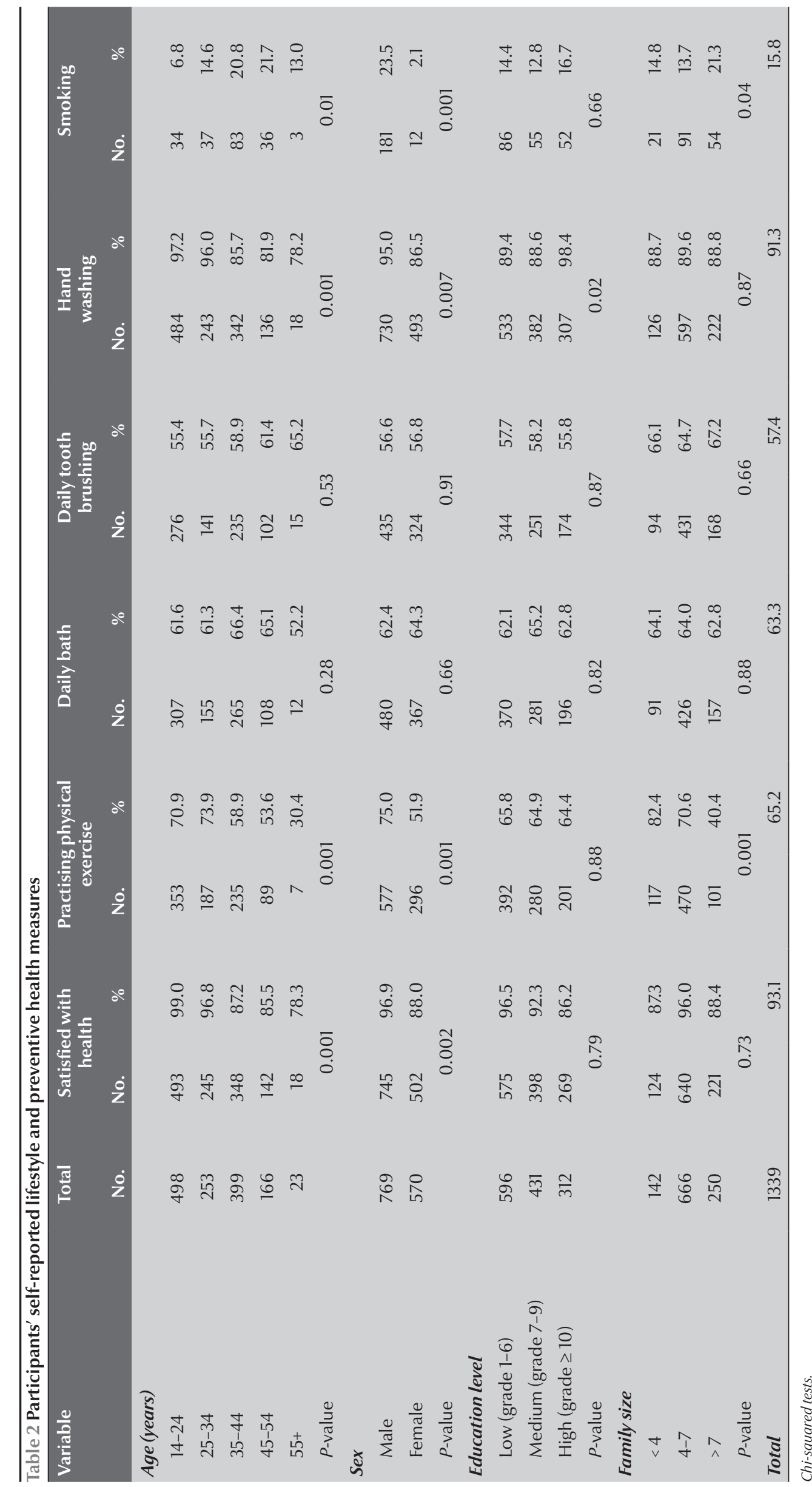




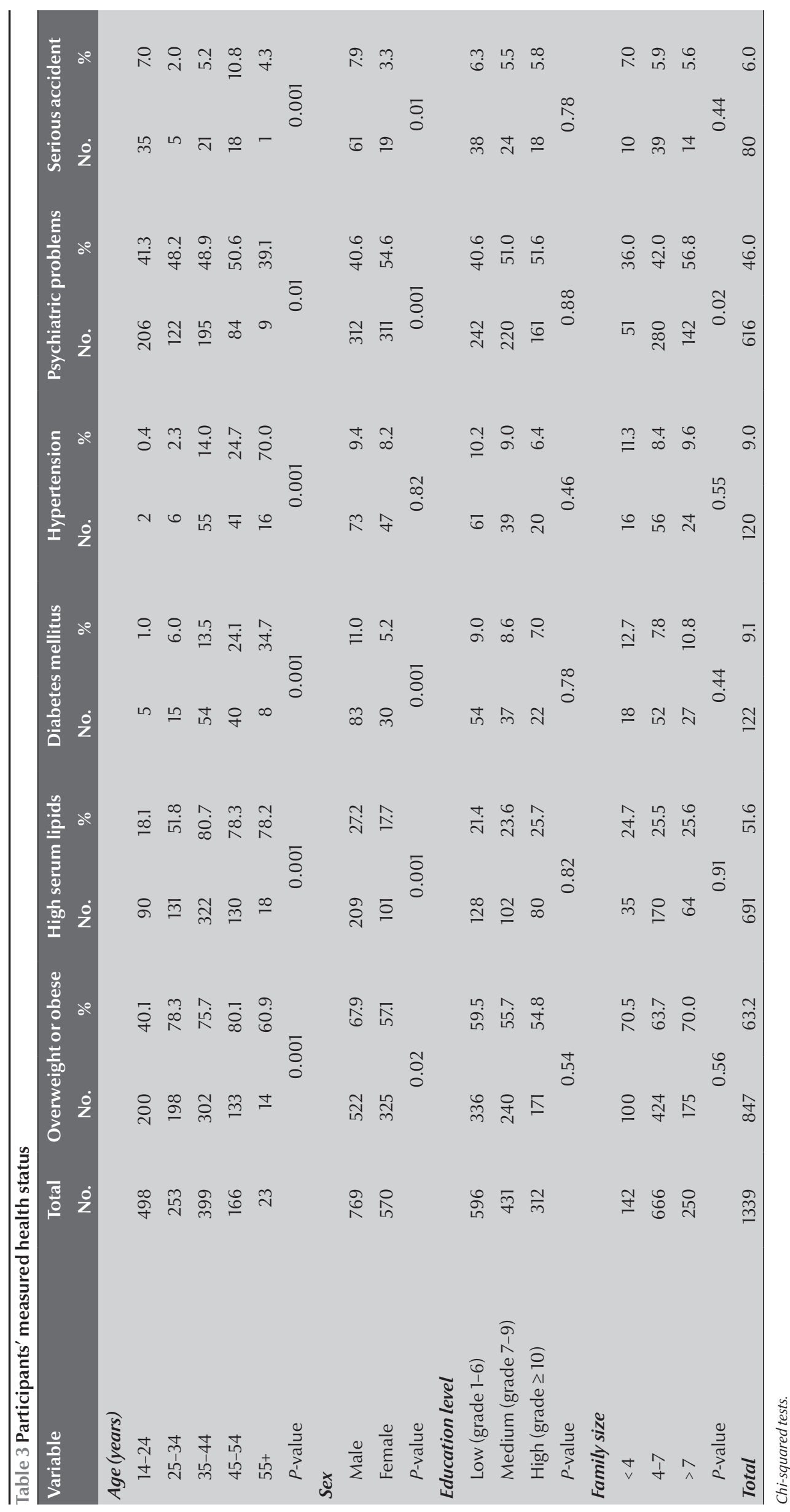




\begin{tabular}{|c|c|c|c|c|c|c|c|c|c|c|c|}
\hline \multirow[t]{2}{*}{ Variable } & \multirow{2}{*}{$\begin{array}{l}\text { Total } \\
\text { No. }\end{array}$} & \multicolumn{2}{|c|}{$\begin{array}{l}\text { Completed } \\
\text { children's } \\
\text { immunization }\end{array}$} & \multicolumn{2}{|c|}{$\begin{array}{l}\text { Breastfed } \\
\text { children for } 6 \\
\text { months }\end{array}$} & \multicolumn{2}{|c|}{$\begin{array}{c}\text { Ever had } \\
\text { mammogram }\end{array}$} & \multicolumn{2}{|c|}{$\begin{array}{c}\text { Ever had cervical } \\
\text { smear }\end{array}$} & \multicolumn{2}{|c|}{$\begin{array}{l}\text { Ever used oral } \\
\text { contraceptives }\end{array}$} \\
\hline & & No. & $\%$ & No. & $\%$ & No. & $\%$ & No. & $\%$ & No. & $\%$ \\
\hline \multicolumn{12}{|l|}{ Age (years) } \\
\hline $14-24$ & 78 & 73 & 93.6 & 68 & 87.2 & 6 & 7.7 & 3 & 3.9 & 14 & 18.0 \\
\hline $25-34$ & 125 & 119 & 95.2 & 107 & 85.6 & 8 & 6.4 & 8 & 6.4 & 24 & 19.2 \\
\hline $35-44$ & 152 & 118 & 77.7 & 104 & 68.5 & 8 & 5.3 & 24 & 15.8 & 32 & 21.0 \\
\hline $45-54$ & 41 & 27 & 65.8 & 24 & 58.5 & 2 & 4.9 & 12 & 29.3 & 10 & 24.3 \\
\hline $55+$ & 11 & 7 & 63.6 & 7 & 63.6 & 1 & 9.0 & 5 & 45.4 & 3 & 27.3 \\
\hline$P$-value & & \multicolumn{2}{|c|}{0.001} & \multicolumn{2}{|c|}{0.01} & \multicolumn{2}{|c|}{0.64} & \multicolumn{2}{|c|}{0.01} & \multicolumn{2}{|c|}{0.72} \\
\hline \multicolumn{12}{|l|}{ Education } \\
\hline Low (grade 1-6) & 103 & 88 & 85.4 & 78 & 75.8 & 5 & 4.9 & 12 & 11.7 & 17 & 16.5 \\
\hline Medium (grade 7-9) & 182 & 166 & 91.2 & 152 & 83.5 & 12 & 6.5 & 25 & 13.7 & 42 & 23.0 \\
\hline High $($ grade $\geq 10$ ) & 102 & 90 & 88.2 & 80 & 78.4 & 8 & 7.8 & 15 & 14.7 & 25 & 24.5 \\
\hline$P$-value & & \multicolumn{2}{|c|}{0.74} & \multicolumn{2}{|c|}{0.12} & \multicolumn{2}{|c|}{0.74} & \multicolumn{2}{|c|}{0.88} & \multicolumn{2}{|c|}{0.48} \\
\hline \multicolumn{12}{|l|}{ Work status } \\
\hline Employed & 53 & 45 & 85.0 & 43 & 81.1 & 4 & 7.5 & 9 & 17.0 & 14 & 26.4 \\
\hline Not working & 334 & 299 & 89.0 & 267 & 80.0 & 21 & 6.3 & 43 & 13.0 & 70 & 21.0 \\
\hline$P$-value & & \multicolumn{2}{|c|}{0.84} & \multicolumn{2}{|c|}{0.91} & \multicolumn{2}{|c|}{0.77} & \multicolumn{2}{|c|}{0.07} & \multicolumn{2}{|c|}{0.08} \\
\hline \multicolumn{12}{|l|}{ Family size } \\
\hline$<4$ & 42 & 36 & 85.7 & 34 & 81.0 & 3 & 7.1 & 5 & 12.0 & 8 & 19.0 \\
\hline $4-7$ & 246 & 222 & 90.2 & 197 & 80.0 & 16 & 6.5 & 31 & 12.6 & 52 & 21.1 \\
\hline$>7$ & 101 & 86 & 85.1 & 79 & 78.0 & 6 & 6.0 & 16 & 16.0 & 24 & 23.8 \\
\hline$P$-value & & \multicolumn{2}{|c|}{0.88} & \multicolumn{2}{|c|}{0.94} & \multicolumn{2}{|c|}{0.82} & \multicolumn{2}{|c|}{0.22} & \multicolumn{2}{|c|}{0.32} \\
\hline Total & 387 & 344 & 88.9 & 310 & 80.2 & 25 & 6.5 & 52 & 13.4 & 84 & 21.7 \\
\hline
\end{tabular}

Chi-squared tests.

participants were physically active, of whom $27.7 \%$ were practising vigorous physical activity and $72.3 \%$ moderate physical activity [14]. Another study, from Riyadh, found that $53.5 \%$ of the participants were totally physically inactive, $27.5 \%$ were irregularly active and only $19.0 \%$ of the entire sample was active on a regular basis [15]. The selfreported prevalence of practising physical exercise was $65.2 \%$ in our study. We hypothesize that the younger age of our study population is the reason for the higher rate of physical activity.

\section{Health problems}

Excess body weight has been linked to several health risks and diseases. The link between overweight and the risk of heart disease (complicated by high blood pressure, high blood lipids and diabetes) is especially important considering that heart disease is the most common cause of death in Saudi Arabia [16]. The literature showed a prevalence of overweight and obesity in Saudi Arabia of $36.9 \%$ and $35.6 \%$ respectively [17].

The overall prevalence of diabetes mellitus in Saudi Arabia is 23.7\% [18]. However, the prevalence of diabetes in our study was $9.1 \%$, and we believe that the younger age of our study population is the reason for this lower rate.

There is a consensus that high blood cholesterol is a major risk factor for heart disease and that lowering blood cholesterol levels in individuals with elevated blood cholesterol reduces the risk of a heart attack. It is desirable to have low total blood cholesterol, triglycerides and low-density lipoprotein (LDL) cholesterol levels, and high values for highdensity lipoprotein (HDL) cholesterol. A recent study revealed that in Saudi Arabia, the prevalence of high cholesterol was $54.0 \%$, while the prevalence of high triglycerides was 40.3\% [19].

High blood pressure is a known risk factor for cardiovascular disease and kidney failure. Detection and control of high blood pressure have important implications for reducing the cardiovascular disease risk within the population and preventing kidney failure. It is therefore recommended that all people over the age of 25 years have their blood pressure checked as part of any routine health examination and that the patient be informed of their blood pressure 
readings. The prevalence of hypertension in Saudi Arabia has been reported to be $26.1 \%$ [20]. However, the prevalence of hypertension in our study was only $9.1 \%$ and, again, the younger age of our population is the most likely reason for this low rate.

\section{Prevention and screening practices}

In Saudi Arabia, cervical cancer occurs in 4.1/100 000 female population. It accounts for $7 \%$ of all newly diagnosed cancers in females and is the 8th leading cause of cancer death in Saudi females [21]. We found that only $13.4 \%$ of female patients had ever undergone a cervical smear. This is similar to the rate of $16.8 \%$ found in the literature for Saudi Arabia [22].

In Saudi Arabia, breast cancer is the most common cancer, ranked first among females and accounting for $20.6 \%$ of all newly diagnosed female cancers [21]. It is the single leading cause of cancer death for women 20-59 years of age and thus poses a major public health concern. A recent publication estimated that the future burden of breast cancer in Saudi Arabia is expected to increase by approximately $350 \%$ by 2025 [23]. Mammogram screening is used to detect breast cancer early, thus improving the chances of successful treatment. We found that only $6.5 \%$ of our female participants had ever undergone mammography. The low utilization of mammography screening in Saudi Arabia has been mainly attributed to lack of education, low awareness among females and the lack of standard national screening programmes [24].

Our data revealed a prevalence of oral contraceptive use of $21.7 \%$. There is other evidence that a majority of Saudi women are using contraception methods but without medical advice; a recent study showed that $36.6 \%$ of Saudi females were using oral contraception pills [25].

A recent study of 5339 children in Saudi Arabia found that 4889 received breast milk at birth, indicating a prevalence of initiation of breastfeeding of 91.6\% [26]. Our study showed that about $80 \%$ of the women breastfed their babies for at least 6 months.

A survey of national immunization coverage in Saudi Arabia in 1991 revealed that the national coverage of correct immunization with 6 vaccines (according to World Health Organization standards) was $85 \%$, with $14 \%$ partially immunized and $1 \%$ unimmunized [27]. Our study found that $88.9 \%$ of the participants had performed complete immunization for their children.

\section{Survey implications}

The NGHMS-2010 has provided a clear picture of the measured health indicators and identified areas where considerable individual and collective effort is needed. We had a relatively young population with a mean age of 30.7 (SD 12.7) years. Despite that, too many participants smoked, were overweight, were inactive and had high levels of risk factors for chronic diseases such as cardiovascular disease, cancer, diabetes mellitus and chronic lung disease. In fact, $31 \%$ of the participants had 1 or more of the major risk factors for heart disease. We found the rates of participation were low in prevention programmes such as cervical cancer and breast cancer screening, and we suggest that measures must be taken to enhance these practices. Another concern is the percentage of participants, particularly young women, who were exhibiting symptoms of psychiatric illnesses.

\section{Future directions}

This survey provided a wealth of data that should be viewed as the beginning of a future research and planning agenda. A concerted effort is needed to improve the health status and practices of National Guard families. A future challenge is the integration of existing sources of information for the purpose of planning and developing effective policies, programmes and supportive environments to improve the health status of all National Guard employees and their families.

\section{Acknowledgements}

The NGHMS-2010 was a collaborative effort among many individuals, researchers, and scientists across the Eastern region of Saudi Arabia. We thank them all. We recognize and applaud the incredible effort and professionalism of the staff that interviewed the survey respondents. Acknowledgement is also extended to the PHC staff who contacted the respondents and provided clinic facilities and support for blood collection and anthropometric measurements. In particular, we extend a special thanks to the study participants who took the time to share valuable information about themselves and their health.

Funding: We thank King Abdullah Medical Research Center for providing the research grant for the study.

Competing interests: None declared.

\section{References}

1. Declaration of Alma-Ata. International Conference on Primary Health Care, Alma-Ata, USSR, 6-12 September 1978. World Health Organization [online] (http://www.who.int/publications/almaata_declaration_en.pdf, accessed 27 March 2013).

2. Boerma JT, Sommerfelt AE. Demographic and health surveys (DHS): contributions and limitations. World Health Statistics Quarterly, 1993, 46:222-226.
3. Canadian health measures survey. Statistics Canada [website] (http://www.statcan.gc.ca/concepts/hs-es/measuresmesures-eng.htm, accessed 4 February 2013).

4. Khoja TA, Farid SM. Saudi Arabia family health survey, 2000. Riyadh, Saudi Arabia, Ministry of Health, 2000.

5. Al-Mazrou Y, Farid S. Saudi Arabia child health survey 1991. Riyadh, Saudi Arabia, Ministry of Health, 1991. 
6. Gulf family health survey. Riyadh, Saudi Arabia, Ministry of Health, 2000.

7. Goals and missions. National Guard Health Affairs [website] (http:/ngha.med.sa, accessed 4 February 2013).

8. Devins GM, Orme CM. Center for epidemiologic studies depression scale. In: Test critiques. Kansas City, Missouri, Test Corporation of America, 1984:144-160.

9. Alberti KG, Zimmet PZ. Definitions, diagnosis, and classification of diabetes mellitus and its complications. Diabetic Medicine, 1998, 15:539-553.

10. Frohlich ED et al. Recommendations for human blood pressure determination by sphygmomanometers. Hypertension, 1988, 11:210A-222A.

11. Calculate your body mass index. National Heart, Lung, and Blood Institute [website] (http://www.nhlbisupport.com/ bmi/bmi-m.htm, accessed 4 February 2013).

12. Bauman A et al.; IPS Group. The International Prevalence Study on Physical Activity: results from 20 countries. International Journal of Behavioral Nutrition and Physical Activity, 2009, 6:21.

13. Al-Hazzaa HM. Prevalence of physical inactivity in Saudi Arabia: a brief review. Eastern Mediterranean Health Journal, 2004, 10:663-670.

14. AboZaid HA, Farahat FM. Physical activity profile among patients attending family medicine clinics in western Saudi Arabia. Saudi Medical Journal, 2010, 31(4):428-433.

15. Al-Rafaee SA, Al-Hazzaa HM. Physical activity profile of adult males in Riyadh City. Saudi Medical Journal, 2001, 22:784-789.

16. Al-Othaimeen AI, Al-Nozha M, Osman AK. Obesity: an emerging problem in Saudi Arabia. Analysis of data from the National Nutrition Survey. Eastern Mediterranean Health Journal, 2007, 13:441-448.
17. Al-Nozha MM et al. Obesity in Saudi Arabia. Saudi Medical Journal, 2005, 26:824-829.

18. Al-Nozha MM et al. Diabetes mellitus in Saudi Arabia. Saudi Medical Journal, 2004, 25:1603-1610.

19. Al-Nozha MM et al. Hyperlipidemia in Saudi Arabia. Saudi Medical Journal, 2008, 29:282-287.

20. Saeed AA et al. Prevalence, awareness, treatment, and control of hypertension among Saudi adult population: a national survey. International Journal of Hypertension, 2011, 1:174135.

21. Ministry of Health National Cancer Registry Cancer Incidence Report. Saudi Arabia, 1999-2000. Riyadh, Saudi Arabia, King Fahad National Library, 2004.

22. Sait KH. Attitudes, knowledge, and practices in relation to cervical cancer and its screening among women in Saudi Arabia. Saudi Medical Journal, 2009, 30:1208-1212.

23. Ibrahim EM et al. The present and the future of breast cancer burden in the Kingdom of Saudi Arabia. Medical Oncology, 2008, 25:387-393.

24. Khadiga D, Al-Mohaimeed A. Knowledge, attitudes and practices surrounding breast cancer and screening in female teachers of Buraidah, Saudi Arabia. International Journal of Health Sciences, 2007, 1:76-85.

25. Al-Turki HA. Contraception: attitudes and experiences of Saudi Arabian women. Health Care for Women International, 2011, 32:134-139.

26. El Mouzan Ml et al. Trends in infant nutrition in Saudi Arabia: compliance with WHO recommendations. Annals of Saudi Medicine, 2009, 29:20-23.

27. Farag $M K$ et al. National Immunization Coverage Survey Saudi Arabia, 1991. Journal of Tropical Pediatrics, 1995, 41(Suppl. 1):59-67. 